\title{
Personality type, social support and other correlates of risk for affective disorders in early puerperium
}

\author{
Karolina Maliszewska ${ }^{1}$, Mariola Bidzan², Małgorzata Świątkowska-Freund ${ }^{1}$, Krzysztof Preis ${ }^{1}$ \\ ${ }^{1}$ Department of Obstetrics, Medical University of Gdansk, Poland \\ ${ }^{2}$ Institute of Psychology, University of Gdansk, Poland
}

\begin{abstract}
Objectives: The purpose of this study was to assess the prevalence of risk for postpartum mood disorders in mothers during the early postnatal period and to search for coexisting conditions.

Material and methods: We studied 546 women in the first week after delivery. The subjects filled out a questionnaire concerning their health, social and demographic status, the Edinburgh Postnatal Depression Scale, the Patient Health Questionnaire, the NEO-FFI Personality Inventory and the Berlin Social Support Scales.

Results: Probable mood disorders affected $15.85 \%$ of these patients. The risk increased with a current cesarean section $(\mathrm{ORa}=2.54)$, a higher level of neuroticism $(\mathrm{ORa}=1.65)$, greater fear of childbirth $(\mathrm{ORa}=1.18)$, a lower level of extraversion $(\mathrm{ORa}=0.77)$ and greater need for social support (ORa $=2.68)$.

Conclusions: High level of neuroticism and introversion, as well as higher fear of delivery and the need of social support are among factors increasing the probability of mood disturbances in early postpartum period. A cesarean section might elevate the risk similarly. The mental health of such patients should be carefully examined.
\end{abstract}

Key words: Edinburgh Postnatal Depression Scale, pregnancy complications, affective disorders

Ginekologia Polska 2016; 87, 12: 814-819

\section{INTRODUCTION}

The spectrum of postpartum mood disorders includes, in order of severity, "baby blues", hypomania, depression and psychosis. They differ mainly in terms of the severity of symptoms, onset time, and persistence [1-3]. The "baby blues" (otherwise known as maternal, maternity, postpartum or postnatal blues) typically begins a few days after delivery and lasts up to 10-14 days [1] and can be regarded as a mild and brief postpartum disorder [4]. Postpartum (or postnatal) depression is characterized by typical depressive symptoms, and affects not only the mother, but also the baby and their family. It may appear up to one year after labor in $6.5 \%$ to $12.9 \%$ of cases [5, 6]. A patient suffering from this kind of depression will need specialized intervention.

There are no consistent results from existing research regarding the risk factors for postpartum mood disorders. Researchers mention such factors as emotional problems during pregnancy (especially depressive symptoms) and sociodemographic factors (e.g. stressful life events, lonely motherhood [1, 2], cohabitation [7]). As for the psychological causes of postnatal mood disorders, a high level of neuroticism or a low level of extraversion have been mentioned $[1,2,8,9]$, as well as the lack of social support, especially the patient's perception of being supported, the need for support and other aspects [9].

In 1987, Cox, Holden, Sagovsky et al. developed a screening test: the Edinburgh Postnatal Depression Scale (EPDS). It consists of 10 questions, and the score may range from 0 to 30 points. This instrument does not contain items concerning fatigue, changes in sleep, appetite or libido, as these common feelings may be natural shortly after birth [10]. Thirteen, twelve or ten points is most often treated as the cut-off score for diagnosing the risk of postpartum depression [11]. If the patient is found to be at risk, further clinical assessment is required [1, 12]. 
The purpose of this study was to investigate the prevalence of risk for postpartum mood disorders and to identify correlating factors.

\section{MATERIAL AND METHODS}

The study was designed as a cross-sectional study. Women over 18 years old, who gave birth between May 2013 and June 2014, were invited to join the study. They were informed about the purpose and structure of the study. Written consent was provided by 567 subjects, 18 of which were excluded because of the exclusion criteria: death of a newborn child, illness of a child requiring special parental care, or a preterm labor earlier than 32.0 weeks of pregnancy. The study was approved by the institutional Ethics Board.

The patients had an average score of 7.98 (SD 4.39) points in the EPDS scale, with a range of 0 to 26 points. They responded to the questionnaire an average of 2.69 days after birth (range: 0 to 15). They were 30.2 years old (range: 18-46). On average, these women gave birth in the 39.06 week of pregnancy (range: 32.0-42.0); this was more often a vaginal birth (68.7\%), and more than half of the subjects were primiparae (54.1\%). Most of the subjects $(76.5 \%)$ resided in a city with a population above 100,000 . Most of them (79\%) had a higher education (79\%), were employed (82.2\%) and married (80.1\%).

The instruments used in the study included the Edinburgh Postnatal Depression Scale (EPDS), an authorial questionnaire on social and medical problems, a list of the most common emotions in depression and three standardized psychological scales: the NEO-FFI Personality Inventory, the Berlin Social Support Scales (BSSS) and the Patient Health Questionnaire-9 (PHQ-9). In the EPDS, a score of 13 was chosen as the cut-off point. A single examination with the EPDS does not lead to a diagnosis of postpartum depression, since it measures only the likelihood or the occurrence of possible symptoms $[11,13]$. Even though the examination was carried out within the usual time of onset of postpartum blues, we may not have detected it. Therefore, we decided to use the more general term "postpartum mood/affective disorders". The PHQ-9 is a tool used in screening for depression and contains 9 questions with criteria for depression from DSM IV. It is available at http://www.phqscreeners. com/. It may be shortened to a two-question version, the PHQ-2 [14]. The NEO-FFI Personality Inventory test measures personality in five dimensions: neuroticism $(\mathrm{N})$, extraversion $(E)$, openness to experience $(O)$, agreeableness $(A)$, conscientiousness $(C)$. The raw points are converted into a standardized 10-point scale. As required, the individual forms were purchased for specific use in the study [15]. The BSSS measures the following parameters of social support: perceived available support, the need for support, support seeking, currently received support, buffering-protective.
Some of the scales mentioned above includes subscales for emotional support, informative support, instrumental support, and satisfaction with support. The result is given as the arithmetic mean of a scale or a subscale [16]. Sleep quality, the quality of feeding a newborn and satisfaction with one's financial situation were measured in a 10-point scale similar to the Numerical Rating Scale (NRS) used to measure subjective pain. This article will give only the results from the first week of puerperium; however, further research was carried out in the third week, third month, and sixth month after delivery to identify later mood disorders.

A statistical analysis was conducted using the STATISTICA 12.0 software. The Shapiro-Wilk test was used to check normal distribution, and t-Student test and U Mann-Whitney test for intergroup differences if the variables were continuous, and $\mathrm{Chi}^{2}$ when categorical. To determine correlation in data without normal distribution, we used rho Spearman. The risk factors were analyzed using the odds ratio (OR), broken down as follows: univariate (unadjusted, OR crude, $\mathrm{ORc}$ ); bivariate (adjusted to neuroticism, OR adjusted, ORa); multivariate (ORa) logistic regression.

The personality trait of neuroticism was assumed a priori as a main confounder for psychological data. The data are presented here as an arithmetical mean with standard deviation (SD) or as a number with the percentage of the sample ( $n(\%)$ ), or as percentages only (\%). A two tailed $p<0.05$ was assumed to be the threshold of statistical significance.

\section{RESULTS}

The risk of postpartum mood disorders was found in 87 patients $(15.85 \%)$. Compared to patients who screened negative, these women scored higher in the EPDS (15.18 SD 2.50 vs. 6.62 SD 3.18, respectively, $p=0.00$ ), the PHQ-9 (10.16 SD 4.81 vs. 4.73 SD 3.84, respectively, $\mathrm{p}=0.00$ ) and PHQ-2 (2.34 SD 1.61 vs. 0.90 SD 1.20, respectively, $p=0.00)$. The correlation between the EPDS and PHQ-9 was calculated to be $54.66 \%, p=0.00$, while between the EPDS and the PHQ-2 it was $50.01 \%, p=0.00$. The subjects screened as positive most frequently reported fatigue (89\%) or too little sleep (64\%), and only half of them complained of impaired concentration (46\%) or depressed mood (43\%; see Table 1.). When the cut-off point in the EPDS is put at 10 points, the prevalence of risk rises to $33.3 \%$. Other results based on different cut-off points in the EPDS and the PHQ and present emotions are shown in Table 1.

Compared to the control group, the women at risk for affective disorders were less satisfied with their financial situation ( $p<0.001)$, their sleep $(p=0.01)$ and feeding the baby ( $<0.001$ ); they also used more formula in feeding as well ( $p=0.005)$. The patients reported mental disorders in the past more often ( $14.94 \%$ vs. $4.99 \%, p=0.002)$, as well as previous perinatal mood disorders (70\% vs. $27.49 \%$, 
Table 1. The risk of postpartum mood disorders in screening with different instruments and different cut-off scores used. Frequency of items reported by women screened positive

\begin{tabular}{|l|c|c|c|c|c|c|c|c|}
\hline $\begin{array}{l}\text { Instrument, } \\
\text { cut-off score }\end{array}$ & $\begin{array}{c}\text { Patients with postnatal } \\
\text { mood disorders }\end{array}$ & Low mood & $\begin{array}{c}\text { Loss of } \\
\text { interest }\end{array}$ & Fatigue & $\begin{array}{c}\text { Low self- } \\
\text {-esteem }\end{array}$ & $\begin{array}{c}\text { Impaired } \\
\text { concentration }\end{array}$ & $\begin{array}{c}\text { Suicidal } \\
\text { thoughts }\end{array}$ & $\begin{array}{c}\text { Too little } \\
\text { sleep }\end{array}$ \\
\hline EPDS $>12$ & $\mathbf{n}(\%)$ & & & & $\%$ & & & \\
\hline EPDS $>11$ & $87(15.85)$ & $43^{*}$ & $33^{*}$ & 89 & $34^{*}$ & $46^{*}$ & $5^{*}$ & $64^{*}$ \\
\hline EPDS $>9$ & $113(20.58)$ & $28^{*}$ & $8^{*}$ & $81^{*}$ & $18^{*}$ & 17 & 0,8 & $41^{*}$ \\
\hline PHQ-9> & $183(33.33)$ & $24^{*}$ & $8^{*}$ & $74^{*}$ & 14 & 15 & 0,6 & $38^{*}$ \\
\hline PHQ-2 $>2$ & $86(16.76)$ & $29^{*}$ & $8^{*}$ & $90^{*}$ & $22^{*}$ & $26^{*}$ & $2^{*}$ & $42^{*}$ \\
\hline
\end{tabular}

${ }^{*} \mathrm{p}<0,05$; EPDS — Edinburgh Postnatal Depression Scale; PHQ — Patient Heath Questionnaire

Table 2. Sample characteristics: control group and group at risk for postpartum mood disorders (EPDS > 12). Odds ratio from logistic regression

\begin{tabular}{|c|c|c|c|c|c|c|c|c|c|}
\hline \multirow{3}{*}{$\begin{array}{l}\text { Satisfaction } \\
\text { with financial situation }\end{array}$} & $\begin{array}{l}\text { EPDS } \\
\leq 12\end{array}$ & $\begin{array}{l}\text { EPDS } \\
>12\end{array}$ & \multirow{3}{*}{$\begin{array}{c}p \\
<0.001\end{array}$} & \multicolumn{3}{|c|}{ Unadjusted model } & \multicolumn{3}{|c|}{$\begin{array}{l}\text { Model adjusted for } \\
\text { neuroticism }\end{array}$} \\
\hline & \multicolumn{2}{|c|}{ Mean (SD) or n (\%) } & & ORc & $\mathrm{Cl}$ & p & ORa & $\mathrm{Cl}$ & $\mathbf{P}$ \\
\hline & $6.80(1.78)$ & $5.98(2.17)$ & & 0.80 & $0.71-0.90$ & $<0.001$ & 0.89 & $0.77-1.01$ & 0.08 \\
\hline Informal relationship & $86(18.82 \%)$ & $18(20.69 \%)$ & 0.68 & 1.01 & $0.63-1.96$ & 0.72 & 0.93 & $0.49-1.78$ & 0.83 \\
\hline $\begin{array}{l}\text { Regular cigarette smoking } \\
\text { during pregnancy }\end{array}$ & $33(7.14 \%)$ & $13(14.94 \%)$ & 0.03 & 2.28 & $1.15-4.55$ & 0.02 & 2.21 & $0.99-4.92$ & 0.05 \\
\hline Fear of childbirth & $5.13(2.72)$ & $6.65(2.51)$ & $<0.001$ & 1.23 & $1.12-1.35$ & $<0.001$ & 1.14 & $1.03-1.26$ & 0.009 \\
\hline History of mental disorders & $23(4.99 \%)$ & $13(14.94 \%)$ & 0.002 & 3.35 & $1.62-6.90$ & 0.001 & 1.74 & $0.75-4.07$ & 0.20 \\
\hline $\begin{array}{l}\text { History of perinatal mood } \\
\text { disorders }\end{array}$ & $58(27.49 \%)$ & $28(70.00 \%)$ & $<0.001$ & 6.15 & $2.92-12.96$ & $<0.001$ & 4.35 & $1.91-9.92$ & $<0.001$ \\
\hline Preterm labor > 32.0 week & $43(9.31 \%)$ & $10(11.49 \%)$ & 0.53 & 1.27 & $0.61-2.63$ & 0.53 & 1.26 & $0.55-2.27$ & 0.58 \\
\hline Cesarean section & $135(29.22 \%)$ & $34(42.53 \%)$ & 0.01 & 1.79 & $1.12-2.87$ & 0.01 & 2.17 & $1.27-3.71$ & 0.005 \\
\hline Prenatal classes & $205(44.74 \%)$ & $23(26.74 \%)$ & 0.002 & 0.46 & $0.27-0.76$ & 0.003 & 0.56 & $0.32-0.98$ & 0.04 \\
\hline Length of sleep (hours) & $5.46(2.11)$ & $5.10(2.42)$ & 0.18 & 0.93 & $0.83-1.04$ & 0.18 & 1.01 & $0.89-1.15$ & 0.88 \\
\hline Quality of sleep (0-10) & $5.08(2.1)$ & $4.43(1.9)$ & 0.01 & 0.86 & $0.76-0.97$ & 0.01 & 0.90 & $0.78-1.03$ & 0.12 \\
\hline Breastfeeding exclusive & $162(54.36 \%)$ & 17 (32.08\%) & 0.003 & 0.40 & $0.21-0.74$ & 0.004 & 0.50 & $0.25-0.98$ & 0.047 \\
\hline $\begin{array}{l}\text { Amount of formula in daily } \\
\text { feeding (\%) }\end{array}$ & $31.31(44.02)$ & $51.59(46.29)$ & 0.005 & 1.01 & $1.00-1.02$ & 0.008 & 1.00 & $1.00-1.02$ & 0.06 \\
\hline $\begin{array}{l}\text { Quality of feeding } \\
\text { a newborn (0-10) }\end{array}$ & $6.63(2.93)$ & $5.38(3.46)$ & $<0.001$ & 0.88 & $0.82-0.95$ & 0.001 & 0.90 & $0.83-0.98$ & 0.01 \\
\hline
\end{tabular}

EPDS — Edinburg Postnatal Depression Scale; ORc — crude odds ratio; $\mathrm{Cl}$ — confidence interval; ORa — adjusted odds ratio

$p<0.001)$, fear of delivery $(p<0.001)$, and regular cigarette smoking during pregnancy (14.94\% vs. $7.14 \%, p=0.03$ ). A larger percentage of the women at risk had undergone a cesarean section $(42.53 \%$ vs. $26.74 \%, p=0.01)$. They were less likely to be breastfeeding exclusively (32.08\% vs. $54.36 \%$, $\mathrm{p}=0.003)$ or to have attended a prenatal class $(26.74 \%$ vs. 44.74, $p=0.002$ ).

The following factors were observed to correlate with the risk of postpartum mood disorders: lower satisfaction with their financial situation $(\mathrm{ORc}=0.80)$; perception of poor sleep $(\mathrm{ORc}=0.86)$; dissatisfaction with feeding the baby $(\mathrm{ORc}=0.88, \mathrm{ORa}=0.90)$ (use of formula, $\mathrm{ORc}=1.01)$; greater fear of the delivery $(\mathrm{ORC}=1.23, \mathrm{ORa}=1.14)$. We should not forget that such complaints may reflect general depressive cognitive schemes. Further correlates include: regular cigarette smoking during the pregnancy $(\mathrm{ORc}=2.28)$; mental disorders in the past $(\mathrm{ORc}=3.35)$, including previous perinatal mood disorders (ORc $=6.15$, ORa $=4.35)$; a cesarean section $(\mathrm{ORc}=1.79, \mathrm{ORa}=2.17)$. On the other hand, exclusive breastfeeding $(\mathrm{ORc}=0.40, \mathrm{ORa}=0.50)$ and attending a prenatal class $(\mathrm{ORc}=0.46, \mathrm{ORa}=0.56)$ correlate with lower risk of mood disorders (Tab. 2).

Personality traits were then investigated. Women with postpartum mood disorders presented a significantly higher 
Table 3. Comparison of the NEO-FFI results of women at risk and no risk for postpartum mood disorders (EPDS $>12$ ). Odds ratio from logistic regression

\begin{tabular}{|c|c|c|c|c|c|c|c|c|c|}
\hline & $\begin{array}{c}\text { EPDS } \leq 12 \\
N=459\end{array}$ & $\begin{array}{c}\text { EPDS }>12 \\
N=87\end{array}$ & \multirow[b]{2}{*}{$\mathbf{p}$} & \multicolumn{3}{|c|}{ Unadjusted model } & \multicolumn{3}{|c|}{ Model adjusted for neuroticism } \\
\hline & \multicolumn{2}{|c|}{ Mean (SD) } & & ORc & $95 \% \mathrm{Cl}$ & $\mathbf{p}$ & ORa & $95 \% \mathrm{Cl}$ & $\mathbf{p}$ \\
\hline N & $3.79(1.8)$ & $6.03(1.57)$ & $<0.001$ & 1.98 & $1.70-2.31$ & $<0.001$ & - & & \\
\hline $\mathrm{E}$ & $6.34(1.75)$ & $5.08(1.8)$ & $<0.001$ & 0.66 & $0.58-0.77$ & $<0.001$ & 0.81 & $0.69-0.96$ & 0.01 \\
\hline 0 & $5.26(1.94)$ & $4.83(2.13)$ & 0.06 & 0.90 & $0.80-1.01$ & 0.06 & 0.94 & $0.83-1.06$ & 0.34 \\
\hline A & $5.98(2.06)$ & $5.37(2.06)$ & 0.01 & 0.87 & $0.77-0.97$ & 0.01 & 0.96 & $0.85-1.10$ & 0.58 \\
\hline C & $6.81(2.04)$ & 6.33 (1.99) & 0.046 & 0.89 & $0.80-1.00$ & 0.046 & 1.08 & $0.95-1.24$ & 0.25 \\
\hline
\end{tabular}

EPDS - Edinburgh Postnatal Depression Scale; ORc — crude odds ratio; $\mathrm{Cl}$ — confidence interval; $\mathrm{ORa}$ — adjusted odds ratio; $\mathrm{N}$ - neuroticism; $\mathrm{E}$ - extraversion; $\mathrm{O}$ - openness to experience; $\mathrm{A}$ - agreeableness; $\mathrm{C}$ - conscientiousness

Table 4. Comparison of BSSS results of women at risk and no risk for postpartum mood disorders (EPDS > 12). Odds ratio from logistic regression

\begin{tabular}{|c|c|c|c|c|c|c|c|c|c|}
\hline \multirow{2}{*}{ Social support } & \multirow{2}{*}{$\begin{array}{c}\text { EPDS } \leq 12 \\
N=453\end{array}$} & \multirow{2}{*}{$\begin{array}{c}\text { EPDS > } 12 \\
\qquad \begin{array}{c}\mathrm{N}=87\end{array}\end{array}$} & \multirow{2}{*}{$\mathbf{p}$} & \multicolumn{3}{|c|}{ Unadjusted model } & \multicolumn{3}{|c|}{ Model adjusted for neuroticism } \\
\hline & & & & ORc & $95 \% \mathrm{Cl}$ & p & ORa & $95 \% \mathrm{Cl}$ & p \\
\hline Perceived available & $3.75(0.33)$ & $3.59(0.47)$ & $<0.001$ & 0.35 & $0.20-0.61$ & $<0.001$ & 0.79 & $0.42-1.50$ & 0.47 \\
\hline $\begin{array}{l}\text { Perceived available } \\
\text { emotional }\end{array}$ & $3.67(0.4)$ & $3.52(0.48)$ & 0.003 & 0.47 & $0.29-0.78$ & 0.003 & 0.82 & $0.46-1.44$ & 0.48 \\
\hline $\begin{array}{l}\text { Percieved available } \\
\text { instrumental }\end{array}$ & $3.83(0.35)$ & $3.65(0.56)$ & $<0.001$ & 0.41 & $0.245-0.66$ & $<0.001$ & 0.85 & $0.49-1.48$ & 0.56 \\
\hline Need for & $2.99(0.59)$ & $3.25(0.49)$ & 0.000 & 2.37 & $1.49-3.75$ & $<0.001$ & 1.88 & $1.15-3.06$ & 0.01 \\
\hline Support seeking & $2.95(0.64)$ & $3.09(0.54)$ & 0.05 & 1.46 & $0.99-2.15$ & 0.05 & 1.62 & $1.04-2.53$ & 0.03 \\
\hline Currently received & $3.82(0.33)$ & $3.65(0.51)$ & $<0.001$ & 0.39 & $0.23-0.66$ & $<0.001$ & 0.68 & $0.38-1.22$ & 0.20 \\
\hline $\begin{array}{l}\text { Currently received } \\
\text { emotional }\end{array}$ & $3.86(0.32)$ & $3.71(0.49)$ & $<0.001$ & 0.39 & $0.23-0.69$ & $<0.001$ & 0.69 & $0.38-1.27$ & 0.23 \\
\hline $\begin{array}{l}\text { Currently received } \\
\text { informative }\end{array}$ & $3.83(0.4)$ & $3.65(0.57)$ & $<0.001$ & 0.47 & $0.30-0.72$ & $<0.001$ & 0.73 & $0.44-1.21$ & 0.22 \\
\hline $\begin{array}{l}\text { Currently received } \\
\text { instrumental }\end{array}$ & $3.56(0.66)$ & $3.4(0.8)$ & 0.04 & 0.73 & $0.54-0.99$ & 0.045 & 0.92 & $0.66-1.30$ & 0.64 \\
\hline $\begin{array}{l}\text { Satisfaction with } \\
\text { support }\end{array}$ & $3.9(0.39)$ & $3.63(0.74)$ & $<0.001$ & 0.42 & $0.28-0.66$ & $<0.001$ & 0.57 & $0.36-0.91$ & 0.02 \\
\hline Protective buffering & $1.81(0.59)$ & $1.88(0.63)$ & 0.27 & 1.23 & $0.85-1.80$ & 0.27 & 0.99 & $0.45-1.53$ & 0.97 \\
\hline
\end{tabular}

EPDS — Edinburgh Postnatal Depression Scale; ORc — crude odds ratio; $\mathrm{Cl}$ — confidence interval; ORa — adjusted odds ratio

level of neuroticism $(p<0.001)$, and a lower level of extraversion $(p<0.001)$, agreeableness $(p=0.01)$ and conscientiousness ( $p=0.046)$. A high level of neuroticism increased the odds of postpartum affective disorders (ORc $=1.98$ ), whereas extraversion $(\mathrm{ORc}=0.66, \mathrm{ORa}=0.81)$, agreeableness and conscientiousness were found to correlate with lower odds (ORc $=0.87,0.89$ respectively) (Tab. 3 ).

The patients at risk for postpartum affective disorders presented a lower evaluation of following social support dimensions: perceived available support $(p=0.001, O R c=0.35)$, including emotional support $(p=0.003, O R c=0.47)$ and instrumental $(p<0.001, O R c=0.41)$ as well as currently received support $(p<0.001, \mathrm{ORc}=0.39)$, including emotional support $(p<0.001, \mathrm{ORc}=0.39)$, informative support $(p<0.001$,
ORc $=0.47)$, instrumental support $(p=0.04, O R c=0.73)$, and satisfaction with support $(\mathrm{p}<0.001, \mathrm{ORc}=0.42, \mathrm{ORa}=0.57)$. Therefore, when these aspects are assessed as satisfactory or high, there may be a lower risk for postnatal mood disorders. The patients at risk had a greater need for social support $(p<0.001, O R c=2.73 ; O R a=1.88)$, and so they sought it more strenuously (ORa $=1.62)$ (Tab. 4).

Subsequently, we used multivariate logistic regression to build a final model. The potential risk factors for mood disorders in early peuperium are as follows: current cesarean section (ORa $=2.54)$, high level of neuroticism $(\mathrm{ORa}=1.65)$, increased fear of labor (ORa $=1.18)$, low level of extraversion $(\mathrm{ORa}=0.77)$, and high need for social support $(\mathrm{ORa}=2.68)(\mathrm{Tab} .5)$. 
Table 5. Risk for postpartum affective disorders with regard to the selected determinants. Fully adjusted model

\begin{tabular}{|l|c|c|c|}
\hline Parameter & ORa & $95 \%$ Cl & p \\
\hline Cesarean section & 2.54 & $1.17-5.34$ & 0.02 \\
\hline Fear of childbirth & 1.18 & $1.02-1.36$ & 0.03 \\
\hline Neuroticism (NEO-FFI) & 1.65 & $1.32-2.06$ & $<0.001$ \\
\hline Extraversion (NEO-FFI) & 0.77 & $0.62-0.97$ & 0.03 \\
\hline Need for social support (BSSS) & 2.68 & $1.20-5.98$ & 0.02 \\
\hline
\end{tabular}

ORa - adjusted odds ratio; $\mathrm{Cl}$ - confidence interval; NEO-FFI — the personality inventory; BSSS - Berlin Social Support Scales. Model adjusted for satisfaction with the financial situation, history of mental disorders, regular cigarette smoking during pregnancy, prenatal classes, quality of feeding the

baby, NEO-FFI, BSSS. $\mathrm{Chi}^{2}=137.23, \mathrm{df}=26, \mathrm{p}<0.001$, PseudoR ${ }^{2}=0.511$

\section{DISCUSSION}

In the study, we found that most of the sociodemographic factors were not associated with postpartum mood disorders, which is consistent with the literature $[1,5,9,13]$. No consistent relationship was found between these disorders and the type of relationship, which is contrary to some reports [1, 5, $7,17]$. The much larger group of patients (over five times) allowed us to verify our previous results, where we included the risk factors of extraversion, quality of sleep, and the need for social support [9]. Moreover, the influence of social support was indicated $[5,9,18,19]$.

Neuroticism, a personality trait tested by the NEO-FFI Inventory, is strongly associated with perinatal mood disturbances. A neurotic person (i.e. with high score in NEO-FFI neuroticism) has a tendency to present with negative feelings and will cope with stressful events less effectively. This result has been confirmed by other researchers, e.g. Podolska et al. [8], Dudek et al. [20]. Anxiety is an emotion accompanying neuroticism, and often goes with postnatal depression and other disorders, also as a pathology [21-24]. In our project we examined a special type of anxiety associated with labor, which correlated with the risk for affective disorders. It is obvious that a neurotic and fearful person needs social support, therefore the greater this need is, the more important it is to check for mood disturbances. A high level of extraversion linked with positive emotions and energy protects against the symptoms of postpartum depression [8]. A recent cesarean section produces over twice the chances for postpartum mood disorders, which may be explained by post-operative discomfort and longer convalescence in the postnatal period. In the literature, there is no agreement on this aspect $[5,25]$.

Neuroticism may function as a proven moderator for other risk factors [20], and our results tend to bear this out. It seems that under the influence of a mood disorder, the self-assessment of one's personal situation is disturbed. Thus the assessment of the quality of sleep, feeding the newborn, the financial situation, and the quality of social support is worse. However, adding the personality trait of neuroticism as a moderator partially negates this tendency. The design of a cross-sectional study does not allow us to evaluate the direction of cause-and-effect of the studied parameters. Further research is needed and will be a theme for subsequent papers.

The main limitation of our study is the lack of a procedure verifying the results of the EPDS and the PHQ — that is, a psychiatric diagnosis or the use of validated tools. A psychiatric consultation confirming the prediction was only possible in a few cases. A history of perinatal mood disorders could not be verified neither. A term "risk for postpartum mood disorders" may seem controversial, having too broad sense. However, we decided on it in order to comprise the fact that the time of the survey was typical for maternity blues, the tool - for postpartum depression, and the method — single use of the EPDS without structured clinical interview — for a screening solely. There is no consensus in literature on this subject. A term "Major Depressive Disorder with Peripartum Onset" may be found in DSM-5 (Diagnostic and Statistical Manual of Mental Disorders, fifth edition, 2013). Some authors report similar results as perinatal depression screening programme [8], symptoms of perinatal depression [7], or affective disorders [13]. In Matthey's report, we will encounter "perinatal distress", a term that encompasses disorders of depression and anxiety, either during pregnancy or the first 12 months postpartum [27]. Further studies that will clarify management of mental disorders in obstetric wards are needed.

The Edinburgh Postpartum Depression Scale should be validated in the Polish population. Thus a cut-off point could be assessed based on scientific research. In some studies concerning affective disorders in the first week of puerperium, the score of 10 was taken as the cut-off point; still, it would cover only approximately $30 \%$ instead of $50-80 \%$ of patients $[4,13,26]$. We decided to assume 13 points as the cut-off score in view of further evaluations of postpartum depression.

\section{CONCLUSIONS}

High level of neuroticism and fear of childbirth, low extraversion, higher need for social support, and current cesarean section may correlate with the risk of postpartum mood disorders. Attention must be given to the mental condition of such patients as they require a plan for further treatment. 


\section{REFERENCES}

1. Bielawska-Batorowicz E. Psychologiczne aspekty prokreacji. Marynowicz-Hetka E (ed.). Wydawnictwo Naukowe „Śląsk”, Katowice 2006.

2. Koszewska I. O depresji w ciąży i po porodzie. Wydawnictwo Lekarskie PZWL, Warszawa 2010

3. Jaeschke R, Siwek M, Dudek D. Postpartum mood disorders - update 2012. Neuropsychiatria i Neuropsychologia. 2012, 7, 113-121.

4. Henshaw C. Mood disturbance in the early puerperium: a review. Arch Womens Ment Health. 2003, 6, 33-42.

5. Myers ER, Aubuchon-Endsley N, Bastian LA, [et al.]. Efficacy and Safety of Screening for Postpartum Depression. Rockville MD, 2013.

6. Gavin NI, Gaynes BN, Lohr KN, [et al.]. Perinatal depression: a systematic review of prevalence and incidence. Obstet Gynecol. 2005, 106, 1071-1083.

7. Podolska MZ, Majkowicz M,Sipak-Szmigiel O, [et al.]. Cohabitation as a strong predicting factor of perinatal depression. Ginekol Pol. 2009, 80, 280-284.

8. Podolska MZ, Bidzan M, Majkowicz M, [et al.]. Personality traits assessed by the NEO Five-Factor Inventory (NEO-FFI) as part of the perinatal depression screening program. Med Sci Monit. 2010, 16, 77-81.

9. Maliszewska K, Świątkowska-Freund M, Bidzan M, [et al.]. Relationship, social support, amd personality as psychosocial determinants of the risk for postpartum blues. Ginekol Pol. 2016, 87, 442-447.

10. Eberhard-Gran M, Slinning K, Rognerud M. Screening for postnatal depression - a summary of current knowledge. Tidsskr Nor Laegeforen. 2014, 134, 297-301.

11. Cox JL, Holden JM, Sagovsky R. Detection of postnatal depression. Development of the 10-item Edinburgh Postnatal Depression Scale. $\mathrm{Br}$ J Psychiatry. 1987, 150, 782-786.

12. Bielawska-BatorowiczE. Determinanty spostrzegania dziecka przez rodziców wokresie poporodowym. Wydawnictwo Uniwersytetu Łódzkiego, Łódź 1995.

13. Kosinska-Kaczynska K, Horosz E, Wielgos M, [et al.]. Affective disorders in the first week after the delivery: prevalence and risk factors. Ginekol Pol. 2008, 79, 182-185.

14. Gilbody S, Richards D, Brealey S, [et al.]. Screening for depression in medical settings with the Patient Health Questionnaire (PHQ): a diagnostic meta-analysis. J Gen Intern Med. 2007, 22, 1596-1602.

15. Zawadzki B, Strelau J, Szczepaniak P, [et al.]. NEOFFI — Inwentarz Osobowości NEOFFI. Pracownia Testów Psychologicznych Polskiego Towarzystwa Psychologicznego, Warszawa 1998.
16. Łuszczyńska A, Mazurkiewicz M, Kowalska M, [et al.]. Berlińskie Skale Wsparcia Społecznego (BSSS): Wyniki wstępnych badań nad adaptacją skal i ich własnościami psychometrycznymi. Studia Psychologiczne. 2006, 44, 17-27.

17. Rubertsson C, Wickberg B, Gustavsson $P$, [et al.]. Depressive symptoms in early pregnancy, two months and one year postpartum-prevalence and psychosocial risk factors in a national Swedish sample. Arch Womens Ment Health. 2005, 8, 97-104.

18. Gjerdingen $D$, McGovern $P$, Attanasio $L$, [et al.]. Maternal depressive symptoms, employment, and social support. J Am Board Fam Med. 2014, 27, 87-96.

19. Kaźmierczak M, Kiełbratowska B, Karasiewicz K. The other side of the mirror-the role of partner's empathy in transition to parenthood. Health Psychology Report. 2015, 3, 150-157.

20. Dudek D, Jaeschke R, Siwek M, [et al.]. Postpartum depression: identifying associations with bipolarity and personality traits. Preliminary results from a cross-sectional study in Poland. Psychiatry Res. 2014, 215, 69-74.

21. Andersson L, Sundstrom-Poromaa I, Wulff M, [et al.]. Depression and anxiety during pregnancy and six months postpartum: a follow-up study. Acta Obstet Gynecol Scand. 2006, 85, 937-944.

22. Podolska MZ, Majkowicz M, Sipak-Szmigiel O, [et al.]. Ways of coping in stressful situations and anxiety-state or anxiety-trait among women with symptoms of perinatal depression. Ginekol Pol. 2009, 80, 201-206.

23. Koss J, Bidzan M, Smutek J, [et al.]. Influence of perinatal depression on labour-associated fear on labor and emotional attachment to the child in high-risk pregnancies and the first days after delivery. Med Sci Monit. 2016, 22, 1028-1037.

24. Mojs E, Czarnecka-Iwanczuk M, Glowacka MD. The level of anxiety and depression in the early puerperium - preliminary communication. Psychiatr Pol. 2013, 47, 31-40.

25. Carter FA, Frampton CM, Mulder RT. Cesarean section and postpartum depression: a review of the evidence examining the link. Psychosom Med. 2006, 68, 321-330.

26. Petrozzi A, Gagliardi L. Anxious and depressive components of Edinburgh Postnatal Depression Scale in maternal postpartum psychological problems. J Perinat Med. 2013, 41, 343-348.

27. Matthey S. Are we overpathologising motherhood? J Affect Disord. 2010, 120, 263-266. 